\title{
A 'look' into conjunctivitis
}

\section{F Kathrada}

Division of Pharmacology, Department of Pharmacy and Pharmacology, School of Therapeutic Sciences Faculty of Health Sciences, University of the Witwatersrand, South Africa

Corresponding author, email: fatima.kathrada@wits.ac.za

Conjunctivitis is a common condition characterised by inflammation of the conjunctiva and is the most likely diagnosis in a patient with a red eye and discharge. Acute conjunctivitis is usually a self-limiting condition or one that is easily treated with topical ophthalmic preparations in most cases. Viral conjunctivitis is the most common cause of conjunctivitis followed by bacterial conjunctivitis. Purulent discharge and adherence of the eyelids upon awakening are strong indicators of bacterial conjunctivitis, however other similarities in presentation of conjunctivitis often leads to misdiagnoses. Acute viral conjunctivitis is most commonly caused by adenoviruses and allergic conjunctivitis is usually caused by seasonal pollens. Acute viral conjunctivitis is treated symptomatically while the use of topical antibiotics are useful in limiting the duration of conjunctivitis with a bacterial aetiology. Allergic conjunctivitis is also treated symptomatically with topical antihistamine/mast cell stabiliser preparations. Conjunctivitis secondary to sexually transmitted diseases such as chlamydia or gonorrhoea require systemic antimicrobials in addition to topical treatment.

Keywords: conjunctivitis, viral conjunctivitis, bacterial conjunctivitis, allergic conjunctivitis

Conjunctivitis is a condition characterised by inflammation of the conjunctiva, the mucous membrane that lines the inside surface of the lids and covers the surface of the globe up to the limbus. ${ }^{1}$ It is the most likely diagnosis in a patient with a red eye and discharge. The prevalence of conjunctivitis varies according to the underlying cause which may be influenced by the patient's age as well as the season of the year. ${ }^{1}$

\section{Aetiology and clinical manifestations}

Acute conjunctivitis can be classified as infectious or noninfectious and further divided into four types as outlined in Table 1.1-3 The condition can also be classified as acute, hyperacute or chronic depending on the mode of onset and severity of clinical response. Furthermore, it can be primary or secondary to systemic diseases such as chlamydia or gonorrhoea, in which case systemic treatment is warranted. ${ }^{4}$

Table 1: Classification of conjunctivitis ${ }^{1-4}$

\begin{tabular}{ll}
\hline \multicolumn{1}{c}{ Infectious } & \multicolumn{1}{c}{ Non-infectious } \\
\hline Bacterial & Allergic \\
- Acute bacterial & - Acute \\
- Hyperacute (gonococcal) & - Seasonal \\
- Chronic & - Perennial \\
Viral & Non-allergic \\
- Acute (adenovirus) & - Toxin \\
- Herpes virus & - Foreign object \\
& - Chemicals \\
\hline
\end{tabular}

Clinical experience suggests that most infectious conjunctivitis is viral in both adults and children. However, published studies suggest that the majority of cases in children are bacterial. ${ }^{1-3}$

\section{Bacterial conjunctivitis}

Bacterial conjunctivitis is commonly caused by Staphylococcus aureus, Streptococcus pneumoniae, haemophilus influenzae, and Moraxella catarrhalis. S. aureus is common in adults and the other pathogens in children. ${ }^{5}$ Bacterial conjunctivitis can be contracted directly from the infected individual or can result from abnormal proliferation of the native conjunctival flora. ${ }^{2}$ Contaminated fingers, oculogenital spread and contaminated fomites are common routes of transmission. ${ }^{6,7}$ The course of the disease usually lasts 7 to 10 days. ${ }^{8}$

Bacterial conjunctivitis presents as a red eye with purulent or mucopurulent discharge and chemosis. The condition usually is unilateral at first, then spreads bilaterally with adherence of eyelids and lack of itching. Severe purulent discharge should always be cultured and gonococcal conjunctivitis be considered. Conjunctivitis not responding to standard antimicrobial treatment in sexually active patients warrants a chlamydial evaluation. ${ }^{9}$ The risk of bacterial keratitis is high in contact lens wearers who should be treated with topical antimicrobials and referred to an ophthalmologist. ${ }^{10}$

Hyperacute bacterial conjunctivitis presents with a severe copious purulent discharge and decreased vision. There is often accompanied swelling, pain and preauricular adenopathy. ${ }^{11}$ It is often caused by Neisseria gonorrhoea and carries a high risk of corneal involvement. ${ }^{11}$ Chronic conjunctivitis involves any bacterial conjunctivitis that lasts more than 4 weeks. The most common causes are S. aureus, Moraxella lacunata and enteric bacteria which requires ophthalmologic referral. ${ }^{11}$ 


\section{Viral conjunctivitis}

Viral conjunctivitis is typically caused by adenovirus, with many serotypes implicated. ${ }^{12}$ The conjunctivitis may be part of a viral prodrome followed by adenopathy, fever, pharyngitis, and upper respiratory tract infection, or the eye infection may be the only manifestation of the disease. Viral conjunctivitis is contagious and is spread by direct contact with the patient and his or her secretions or with contaminated objects and surfaces. ${ }^{13}$ Viral conjunctivitis typically presents as watery or mucoserous discharge and a burning, sandy, or gritty feeling in one eye. Patients may report crusting particularly in the morning followed by watery discharge, or perhaps some scanty mucous throughout the day. ${ }^{12,13}$ The second eye usually becomes involved within 24 to 48 hours. The tarsal conjunctiva may have a follicular appearance. There may be an enlarged and tender preauricular node. Viral conjunctivitis is a self-limiting process. ${ }^{13}$

Epidemic keratoconjunctivitis is a form of viral conjunctivitis that causes keratitis in addition to conjunctivitis. It is typically caused by adenovirus types 8,19 and $37 .{ }^{14}$ In addition to typical symptoms of viral conjunctivitis, these patients develop a foreign body sensation which can preclude opening the eyes spontaneously and multiple corneal infiltrates which may degrade acuity. Keratitis is potentially vison-threatening and must be referred to an ophthalmologist. ${ }^{14}$

Herpes conjunctivitis caused by the Herpes simplex virus contributes to 1.3 to $4 \%$ of all viral conjunctivitis cases. ${ }^{15-18}$ Conjunctivitis is usually unilateral with a thin, watery discharge accompanied by vesicular eyelid lesions. Topical corticosteroids should be avoided as they may potentiate the virus., ${ }^{6,19}$

\section{Allergic conjunctivitis}

Allergic conjunctivitis is caused by airborne allergens contacting the eye that, with specific lgE, cause local mast cell degranulation and release of chemical mediators including histamine, eosinophil chemotactic factors, and platelet activating factor among others. ${ }^{20}$ It typically presents as bilateral redness, watery discharge, and pruritus. Pruritus is the cardinal symptom of allergy, distinguishing it from a viral aetiology. Patients with allergic conjunctivitis have a history of atopy, seasonal allergy, or specific allergy such as cats. Similar to viral conjunctivitis, allergic conjunctivitis causes a follicular appearance on the tarsal conjunctiva. ${ }^{21}$ Some cases of allergic conjunctivitis may present with marked chemosis (conjunctival oedema). ${ }^{20,21}$

\section{Drug-, toxin-, or chemical-induced conjunctivitis}

A variety of topical medications such as antibiotic eyedrops, topical antivirals and lubricating eyedrops can induce allergic responses largely due to the presence of benzalkonium chloride in eye peparations. ${ }^{22}$ Cessation of receiving the offending agent leads to resolution of symptoms. ${ }^{6,22} \mathrm{~A}$ patient with an ocular foreign body that was spontaneously expelled may have redness and discharge for up to 12 to 24 hours. ${ }^{6,22}$

\section{Diagnosis}

A detailed examination should be carried out on patients presenting with acute or chronic conjunctivitis. Additional testing is usually not necessary to diagnose routine cases of conjunctivitis. ${ }^{6,8}$ The diagnosis can be made in a patient with a red eye and discharge only if the vision is normal and there is no evidence of keratitis, iritis, or acute angle closure glaucoma. ${ }^{8}$ The type of ocular discharge and ocular symptoms can be used to diagnose the type of conjunctivitis. ${ }^{8,23} \mathrm{~A}$ purulent discharge is often indicative of a bacterial conjunctivitis whereas a watery discharge is more characteristic of a viral conjunctivitis; with pruritis mostly associated with allergic conjunctivitis. . $3,24,25^{2}$ However, the clinical presentation is often non-specific leading to inaccurate diagnosis in many cases. Table 2 illustrates the differences in presentation of each of the types of conjunctivitis to assist in diagnosing the type of conjunctivitis.

\section{Pharmacotherapy}

Viral, allergic and nonspecific conjunctivitis are self-limited processes whereby specific therapy reduces symptoms but does not alter the clinical course. Bacterial conjunctivitis is also a selflimited process in most cases, but topical antimicrobial therapy may shorten the clinical course if given before day six. ${ }^{27,28}$ Therapy should be directed at the likely aetiology of the conjunctivitis as suggested by the history and physical exam. ${ }^{27}$

Allergic conjunctivitis treatment involves avoidance of the offending agent and the use of artificial tears to dilute the allergen. ${ }^{20}$ Topical vasoconstrictors, antihistamines, mast cell stabilisers, NSAIDs and corticosteroids may be indicated. ${ }^{21,29-31}$ In a large systematic review, both mast cell stabilisers and antihistamines were superior to placebo in reducing the symptoms of allergic conjunctivitis. ${ }^{29}$ Acute allergic conjunctivitis is usually self-limiting. In mild cases, topical antihistamine and vasoconstrictor combinations are the mainstay treatment. ${ }^{32,33}$ In patients with seasonal and perennial conjunctivitis, dual-acting

Table 2: Signs and symptoms of common types of conjunctivitis ${ }^{23-26}$

\begin{tabular}{|c|c|c|c|}
\hline & Viral & Allergic & Bacterial \\
\hline Laterality & Unilateral, then bilateral & bilateral & Unilateral, then bilateral \\
\hline Tissue response & $\begin{array}{l}\text { Follicles, chemosis, petechial } \\
\text { haemorrhage, subepithelial infiltrates }\end{array}$ & $\begin{array}{l}\text { Papillae chemosis, tissue } \\
\text { scarring (if severe) }\end{array}$ & $\begin{array}{l}\text { Papillae, subepithelial infiltrates } \\
{ }^{*} \text { mixed papillar and follicular response with } \\
\text { chlamydia }\end{array}$ \\
\hline Discharge & Serous, mucoserous & Serous, mucoserous & Purulent, mucopurulent \\
\hline $\begin{array}{l}\text { Preauricular } \\
\text { lymphadenopathy }\end{array}$ & Common & Unusual & $\begin{array}{l}\text { Unusual } \\
\text { *Occasional in Neisseria and chlamydia }\end{array}$ \\
\hline Symptoms & $\begin{array}{l}\text { Tearing, lid crusting upon awakening, } \\
\text { sandy, gritty feeling in eyes }\end{array}$ & Itching, tearing, discharge & Tearing, lid crusting, purulent discharge \\
\hline
\end{tabular}


topical antihistamines with mast cell stabilising properties are the mainstay of treatment or alternatively a topical mast cell stabiliser. ${ }^{32,33}$ Topical corticosteroids should be used with caution and judiciously as they can cause glaucoma and cataracts. ${ }^{29}$

Table 3: Pharmacotherapy guide in treating allergic conjunctivitis 21,27-33 $^{2}$

\begin{tabular}{llc}
\hline \multicolumn{1}{c}{ Class } & \multicolumn{1}{c}{ Agent } & Dosing frequency \\
\hline Antihistamines & - Emedastine & bd \\
& - Levocabastine & bd \\
Antihistamine and & - Antazoline/Naphazoline & qid \\
vasoconstrictor & - Antazoline/Tetryzoline & qid \\
combination & & \\
Antihistamines with & - Azelastine & bd \\
mast cell stabilising & - Epinastine & bd \\
activity & - Ketotifen & bd \\
& - Olopatadine & bd \\
Mast cell stabilizers & - Lodoxamide & qid \\
& - Sodium cromoglycate & qid \\
\hline
\end{tabular}

Viral conjunctivitis is treated by supportive treatment including preservative-free lubricants, cold presses, ocular antihistamines or vasoconstrictors. ${ }^{29,34}$ Viral conjunctivitis caused by Herpes simplex or Herpes zoster viruses is treated with both topical and oral antivirals to shorten the course of the disease. ${ }^{6}$
Bacterial conjunctivitis is usually self-limiting in at least $60 \%$ of cases within one to two weeks of presentation. Although topical antibiotics shorten the duration of the disease, no differences have been observed in outcomes between treatment and placebo groups. ${ }^{28,35}$ All broad-spectrum antibiotic eye preparations seem to be effective in treating bacterial conjunctivitis. Factors that influence antibiotic choice include availability, patient allergies, resistant patterns and cost. ${ }^{28}$ Chloramphenicol drops/ointment is usually inexpensive and well tolerated as first choice in the treatment of bacterial conjunctivitis. In contact lens wearers, once keratitis has been ruled out, it is reasonable to treat with a topical fluoroquinolone due to the high incidence of Pseudomona infections in these patients..$^{28,35}$

In patients with Chlamydia trachomatis infection, systemic therapy is required, usually with azithromycin, erythromycin or doxycycline. ${ }^{6}$ Patients and their sexual partners must be treated and a co-infection with gonorrhoea must be investigated. ${ }^{6}$

Treatment of conjunctivitis caused by N. gonorrhoea consists of both topical and oral antibiotics. ${ }^{11,36} \mathrm{~N}$. gonorrhoea is associated with a high risk of corneal perforation. ${ }^{36}$

\section{Non-pharmacological recommendations}

Effective management of conjunctivitis requires appropriate patient education. Patient education regarding proper hygiene

Table 4: Ophthalmic therapies for infectious conjunctivitis ${ }^{4,6,28,29,34-36,37-42}$

\begin{tabular}{|c|c|c|c|}
\hline Type & Cause & Treatment options & Dosing \\
\hline \multicolumn{4}{|c|}{ Bacterial conjunctivitis } \\
\hline \multirow[t]{13}{*}{ Acute } & S. aureus & Chloramphenicol $1 \%$ ointment & $\mathrm{q} 8 \mathrm{~h} / 5$ days \\
\hline & S. epidermis, & Chloramphenicol $0.5 \%$ drops & $\mathrm{q} 2 \mathrm{~h}-\mathrm{q} 4 \mathrm{~h} / 5$ days \\
\hline & H. influenza, & Fluoroquinolones: & $\mathrm{q} 4 \mathrm{~h} / 2$ days then \\
\hline & S. pnemoniae, & Ciprofloxacin $0.3 \%$ drops & $\mathrm{q} 6 \mathrm{~h} / 5$ days \\
\hline & S. viridans, & Ofloxacin $0.3 \%$ drops & \\
\hline & & Gatifloxacin & \\
\hline & & Moxifloxacin & \\
\hline & & Fusidic acid $1 \%$ drops & bd until resolves \\
\hline & & Aminoglycosides: & $\mathrm{q} 4 \mathrm{~h}$ \\
\hline & & Framycetin & oint: q8h/7days \\
\hline & & Tobramycin & \\
\hline & & Neomycin & \\
\hline & & Bacitracin/polymyxin B ointment & q3h-q4h/7-10days \\
\hline \multirow[t]{2}{*}{ Chlamydial inclusion } & C. trachomatis & Azithromycin $1 \mathrm{~g}$ orally & Once \\
\hline & & Doxycycline $100 \mathrm{mg}$ orally & bd/7days \\
\hline \multirow[t]{3}{*}{ Gonococcal } & N. gonorrhoea & Ceftriaxone $1 \mathrm{~g}$ & Once \\
\hline & & Irrigation: sodium chloride $0.9 \%$ & \\
\hline & & Dual therapy to cover chlamydia is indicated & \\
\hline \multicolumn{4}{|c|}{ Viral conjunctivitis } \\
\hline \multirow[t]{4}{*}{ Acute } & Adenovirus & Irrigation: sodium chloride $0.9 \%$ & \\
\hline & & Cold compress & \\
\hline & & Antihistamines/vasoconstrictors: oxymetazoline $0.025 \%$ drops & q6h/7days \\
\hline & & Artificial tears & \\
\hline \multirow[t]{3}{*}{ Herpes } & Herpes simplex virus & Topical acyclovir drops & 9xday \\
\hline & & Oral acyclovir $400 \mathrm{mg}$ & $5 x / d 7-10 d$ \\
\hline & & Oral valacyclovir $500 \mathrm{mg}$ & q8h 7-10d \\
\hline \multirow[t]{2}{*}{ Herpes } & Herpes zoster virus & Oral acyclovir $800 \mathrm{mg}$ & $5 x / d 7-10 d$ \\
\hline & & Oral valacyclovir $1000 \mathrm{mg}$ & q8h 7-10d \\
\hline
\end{tabular}


during the infection can help break the chain of transmission. The practitioner should stress the importance of proper hand washing by patients and family members, using of separate linen and towels and avoiding direct contact with infected material. ${ }^{6,43}$ Patients with contact lenses should be advised to discontinue contact lens wear until the eye is white with no discharge..$^{43-44}$

\section{Conclusion}

Conjunctivitis is a common eye disorder seen by healthcare practitioners, with the most common causes being viral and bacterial conjunctivitis. ${ }^{17,18,45-46}$ Patients with allergic conjunctivitis usually have a history of atopy, seasonal allergy or specific allergies and seldomly seek medical care. ${ }^{20,47}$ The similarities in presentation of the different types of conjunctivitis often leads to inaccurate diagnosis and inappropriate treatment with antibiotics. ${ }^{4,6}$ Conjunctivitis is usually self-limiting with treatment of viral and allergic conjunctivitis aimed at symptomatic relief. ${ }^{6}$ Bacterial conjunctivitis is treated with topical antimicrobials to shorten the duration of the condition, with oral antimicrobials indicated in chlamydial and gonococcal cases. ${ }^{32,48}$

\section{References}

1. Weiss A, Brinser JH, Nazar-Stewart V. Acute conjunctivitis in childhood. J Pediatr. 1993;122:10.

2. Fitch $\mathrm{CP}$, Rapoza $\mathrm{PA}$, Owens $\mathrm{S}$, et al. Epidemiology and diagnosis of acute conjunctivitis at an inner-city hospital. Ophthalmology. 1989;96:1215.

3. Gigliotti F, Williams WT, Hayden FG, et al. Etiology of acute conjunctivitis in children. J Pediatr. 1981;98:531.

4. Azari AA, Barney NP. Conjunctivitis: a systemic review of diagnosis and treatment. JAMA 2013;310:1721-1729.

5. Friedlaender MH. A review of the causes and treatment of bacterial and allergic conjunctivitis. Clin Ther. 1995;17:800.

6. American Academy of Ophthalmology; Cornea/External Disease Panel. Preferred Practice Pattern Guidelines: Conjunctivitis-Limited Revision. San Francisco, CA: American Academy of Ophthalmology; 2011.

7. Sattar SA, Dimock KD, Ansari SA, Springthorpe VS. Spread of acute hemorrhagic conjunctivitis due to enterovirus-70: effect of air temperature and relative humidity on virus survival on fomites. J Med Virol. 1988;25:289-96.

8. Yannof J, Duker JS, eds. Ophthalmology. 2nd ed. Mosby; Spain: 2004. Disorders of the conjunctiva and limbus;397-412.

9. Cronau H, Kankanala RR, Mauger T. Diagnosis and management of red eye in primary care. Am Fam Physician. 2010;81(2):137-44.

10. Høvding G. Acute bacterial conjunctivitis. Acta Ophthalmol. 2008;86(1):5-17.

11. Mannis MJ, Plotnik RD. Bacterial conjunctivitis. Ophthalmology. Lippincott Williams \& Wilkins; 2006.

12. Roba LA, Kowalski RP, Gordon AT, et al. Adenoviral ocular isolates demonstrate serotype-dependent differences in in vitro infectivity titers and clinical course. Cornea. 1995;14:388

13. Azar MJ, Dhaliwal DK, Bower KS, et al. Possible consequences of shaking hands with your patients with epidemic keratoconjunctivitis. Am J Ophthalmol. 1996;121:711.

14. Jernigan JA, Lowry BS, Hayden FG, et al. Adenovirus type 8 epidemic keratoconjunctivitis in an eye clinic: risk factors and control. J Infect Dis. 1993;167:1307.

15. Rönnerstam R, Persson K, Hansson H, Renmarker K. Prevalence of chlamydial eye infection in patients attending an eye clinic, a VD clinic, and in healthy persons. Br J Ophthalmol. 1985;69(5):385-8.

16. Harding SP, Mallinson $\mathrm{H}$, Smith JL, Clearkin LG. Adult follicular conjunctivitis and neonatal ophthalmia in a Liverpool eye hospital, 1980-1984. Eye (Lond). 1987;1:512-21.

17. Uchio $E$, Takeuchi $\mathrm{S}$, Itoh $\mathrm{N}$, et al. Clinical and epidemiological features of acute follicular conjunctivitis with special reference to that caused by herpes simplex virus type 1. Br J Ophthalmol. 2000;84(9):968-72.
18. Woodland RM, Darougar S, Thaker $U$, et al. Causes of conjunctivitis and keratoconjunctivitis in Karachi, Pakistan. Trans R Soc Trop Med Hyg 1992;86(3):317-20.

19. Wilhelmus KR. Diagnosis and management of herpes simplex stromal keratitis Cornea. 1987;6(4):286-91.

20. Bielory $B P, O^{\prime} B r i e n ~ T P$, Bielory L. Management of seasonal allergic conjunctivitis: guide to therapy. Acta Ophthalmol. 2012;90(5):399-407.

21. Bielory L. Allergic conjunctivitis: the evolution of therapeutic options. Allergy Asthma Proc. 2012;33(2):129-39.

22. Baudouin C. Allergic reaction to topical eyedrops. Curr Opin Allergy Clin Immunol. 2005;5(5):459-63.

23. Rietveld RP, van Weert HC, ter Riet G, Bindels PJ. Diagnostic impact of signs and symptoms in acute infectious conjunctivitis: systematic literature search. BMJ. 2003;327(7418):789.

24. O'Brien TP, Jeng BH, McDonald M, Raizman MB. Acute conjunctivitis: truth and misconceptions. Curr Med Res Opin. 2009;25(8):1953-61.

25. Morrow GL, Abbott RL. Conjunctivitis. Am Fam Physician. 1998;57(4):735-46.

26. Primary Care and Ocular Disease Committee, American Optometric Association. Infection control: guidelines for the optometric practice. J Am Optom Assoc 1993;64:853.

27. Rose PW, Harnden A, Brueggemann AB, et al. Chloramphenicol treatment for acute infective conjunctivitis in children in primary care: a randomised doubleblind placebo-controlled trial. Lancet. 2005;366:37.

28. Sheikh A, Hurwitz B, van Schayck CP, et al. Antibiotics versus placebo for acute bacterial conjunctivitis. Cochrane Database Syst Rev. 2012;CD001211.

29. Owen CG, Shah A, Henshaw K, et al. Topical treatments for seasonal allergic conjunctivitis: systematic review and meta-analysis of efficacy and effectiveness. Br J Gen Pract. 2004;54(503):451-6.

30. Yaylali V, Demirlenk I, Tatlipinar S, et al. Comparative study of $0.1 \%$ olopatadine hydrochloride and $0.5 \%$ ketorolac tromethamine in the treatment of seasonal allergic conjunctivitis. Acta Ophthalmol Scand. 2003;81(4):378-82.

31. Donshik PC, Pearlman D, Pinnas J, et al. Efficacy and safety of ketorolac tromethamine $0.5 \%$ and levocabastine $0.05 \%$ : a multicenter comparison in patients with seasonal allergic conjunctivitis. Adv Ther. 2000;17(2):94-102.

32. Abelson MB, Allansmith MR, Friedlaender MH. Effects of topically applied occular decongestant and antihistamine. Am J Ophthalmol. 1980;90:254.

33. Nizami RM. Treatment of ragweed allergic conjunctivitis with $2 \%$ cromolyn solution in unit doses. Ann Allergy. 1981;47:5.

34. Greiner JV, Udell IJ. A comparison of the clinical efficacy of pheniramine maleate/ naphazoline hydrochloride ophthalmic solution and olopatadine hydrochloride ophthalmic solution in the conjunctival allergen challenge model. Clin Ther 2005;27(5):568-77.

35. Sheikh A, Hurwitz B. Topical antibiotics for acute bacterial conjunctivitis: Cochrane systematic review and meta-analysis update. Br J Gen Pract. 2005;55(521):962-4

36. Tarabishy $A B$, Jeng BH. Bacterial conjunctivitis: a review for internists. Cleve Clin J Med. 2008;75(7):507-12.

37. Van Eyk AD. Pharmacotherapeutic options for ophthalmic conjunctivitis. S Afr Fam Pract. 2018;60(2):18-23.

38. Vally M, Irhuma MOE. Allergic Conjunctivitis. S Afr Fam Pract. 2017;59(5):5-10.

39. National Guideline on Management and Control of Eye Conditions at Primary Level. Dec 2005.

40. Segal KL, Lai EC, Starr CE. Management of Acute Conjunctivitis. Curr Ophthalmol Rep. 2014;2:116-23.

41. Booysen DJ. South African Guide to Topical Ophthalmic Drugs. 2nd ed. South Africa: Medspec publishing. 2013.

42. Yeung KK, Weissman BA. Bacterial Conjunctivitis (Pink Eye) Treatment and Management. Medscape. Updated Oct 2017.

43. Cheng KH, Leung SL, Hoekman HW, et al. Incidence of contact-lens-associated microbial keratitis and its related morbidity. Lancet. 1999;354:181.

44. Tabbara KF, El-Sheikh HF, Aabed B. Extended wear contact lens related bacterial keratitis. Br J Ophthalmol. 2000;84:327.

45. Hørven I. Acute conjunctivitis: a comparison of fusidic acid viscous eye drops and chloramphenicol. Acta Ophthalmol (Copenh). 1993;71(2):165-8.

46. Stenson S, Newman R, Fedukowicz H. Laboratory studies in acute conjunctivitis. Arch Ophthalmol. 1982;100(8):1275-7.

47. Rosario N, Bielory L. Epidemiology of allergic conjunctivitis. Curr Opin Allergy Clin Immunol. 2011;11(5):471-6.

48. Cronau $H$, Kankanala RR, Mauger T. Diagnosis and management of red eye in primary care. Am Fam Physician. 2010;81(2):137-44. 